\title{
The Dementia Rating Scale (DRS) in the diagnosis of vascular dementia
}

\author{
Cláudia Sellitto Porto ${ }^{1}$, Paulo Caramelli ${ }^{2}$, Ricardo Nitrini ${ }^{3}$
}

\begin{abstract}
The Dementia Rating Scale (DRS) is considered a very useful instrument to assess patients with dementia. The tasks are grouped into five subscales, each one evaluating different cognitive areas, namely: Attention, Initiation/Perseveration (I/P), Construction, Conceptualization and Memory. Objective: To verify the ability of the DRS in discriminating vascular dementia $(\mathrm{VaD})$ patients from healthy controls and VaD from Alzheimer disease (AD) patients. Methods: The DRS was applied to 68 patients with mild dementia (12 with VaD and 56 with $\mathrm{AD}$ ) and 60 healthy controls. The clinical diagnosis was made by two neurologists based on the patients' history, laboratory and neuroimaging results and neuropsychological tests. Results: In the comparison between VaD patients and controls, the subscales I/P, Memory, Conceptualization and Attention were those displaying best discrimination between the two groups. The cutoff $<124$ yielded $93.3 \%$ of sensitivity and $91.7 \%$ of specificity for the diagnosis of $\mathrm{VaD}$. Only the I/P subscale differentiated VaD from AD patients. Conclusions: The DRS was found to be a useful instrument to discriminate $\mathrm{VaD}$ patients from controls. VaD patients showed worse performance in tasks of executive functions than $\mathrm{AD}$ patients. Executive dysfunction, evaluated through the I/P subscale of the DRS, might be useful in differentiating between $\mathrm{VaD}$ and $\mathrm{AD}$ patients.
\end{abstract}

Key words: dementia, neuropsychological tests, cognitive disorders, Alzheimer disease, vascular dementia.

\section{A Escala de Avaliação de Demência (DRS) e o diagnóstico de demência vascular}

Resumo - A Escala de Avaliação de Demência (Dementia Rating Scale - DRS) é considerada um instrumento de grande valor para avaliação de pacientes com demência. As tarefas estão agrupadas em cinco subescalas, as quais avaliam diferentes domínios cognitivos: Atenção, Iniciativa/Perseveração (I/P), Construção, Conceituação e Memória. Objetivo: Verificar a capacidade da DRS em discriminar pacientes com demência vascular (DV) de controles saudáveis e pacientes com DV de pacientes com doença de Alzheimer (DA). Métodos: A DRS foi administrada a 68 pacientes com demência leve (12 com DV e 56 com DA) e a 60 indivíduos controles saudáveis do ponto de vista cognitivo. Os diagnósticos de DV e de DA foram realizados por dois neurologistas baseandose na história clínica, em exames laboratoriais e de neuroimagem e em testes neuropsicológicos. Resultados: $\mathrm{Na}$ comparação de pacientes com DV e controles, as subescalas I/P, Memória, Conceituação e Atenção foram as que melhor diferenciaram os dois grupos. A nota de corte $<124$ demonstrou sensibilidade de 93,3\% e 91,7\% de especificidade para o diagnóstico de DV. Em relação à comparação de pacientes com DV e DA, apenas a subescala I/P apresentou significância estatística na diferenciação dos dois grupos. Conclusões: A DRS mostrou ser um instrumento útil na discriminação entre pacientes com DV e controles. Pacientes com DV demonstraram pior desempenho em tarefas de funções executivas que pacientes com DA. Disfunção executiva, avaliada através das tarefas da subescala I/P, pode ser útil na diferenciação entre pacientes com DV e DA.

Palavras-chave: demência, testes neuropsicológicos, transtornos cognitivos, doença de Alzheimer, demência vascular.

The Dementia Rating Scale (DRS) ${ }^{1,2}$ is a measure of general cognitive status and has been used both in clinical practice and research. The scale includes 36 tasks which are grouped into five subscales assessing different cognitive domains, namely: Attention, Initiation/Perseveration (I/P), Construction, Conceptualization and Memory.

The value of the DRS has been reaffirmed by several studies that have cited the use of this scale in the diagno-

${ }^{1} \mathrm{PhD}$, Behavioral and Cognitive Neurology Unit, Department of Neurology of the University of São Paulo School of Medicine and Cognitive Disorders Reference Center (CEREDIC), Hospital das Clínicas of the University of São Paulo School of Medicine, São Paulo, SP, Brazil. ${ }^{2} \mathrm{MD}$, PhD, Behavioral and Cognitive Neurology Unit, Department of Internal Medicine, Faculty of Medicine, Federal University of Minas Gerais, Belo Horizonte, MG, Brazil. ${ }^{3} \mathrm{MD}$, $\mathrm{PhD}$, Behavioral and Cognitive Neurology Unit, Department of Neurology of the University of São Paulo School of Medicine, and Cognitive Disorders Reference Center (CEREDIC), Hospital das Clínicas of the University of São Paulo School of Medicine, São Paulo, SP, Brazil.

Claudia Sellitto Porto - Rua Itapeva, 378 / cj. 92 - 01332-000 São Paulo SP - Brazil .E-mail: claudiasporto@uol.com.br 
sis and discrimination of patients with Alzheimer disease (AD) from those with other forms of dementia. Previous investigators have reported that the DRS is able to differentiate patients with $\mathrm{AD}$ from cognitively healthy controls, ${ }^{3,4}$ as well as AD from dementia associated with Parkinson's disease, ${ }^{5}$ Huntington's disease from $\mathrm{AD},{ }^{6}$ and patients with vascular dementia $(\mathrm{VaD})$ from patients with $\mathrm{AD} .^{7,8}$

The main objective of this work is to verify the ability of the DRS to discriminate $\mathrm{VaD}$ patients from controls, and $\mathrm{VaD}$ from $\mathrm{AD}$ patients.

\section{Methods}

The study involved 68 patients ( 39 women and 29 men), aged 54 to 84 years (mean $=72.35 \pm 7.78)$, with schooling ranging from 3 to 17 years (mean $=9.40 \pm 4.78$ ), attended by members of the Behavioral and Cognitive Neurology Unit of the Department of Neurology at the University of São Paulo School of Medicine, in Brazil. All patients were submitted to appropriate laboratory tests and to structural neuroimaging (computed tomography (CT) or magnetic resonance (MR) of the skull). Moreover, they were submitted to a comprehensive neuropsychological evaluation, which included the following tests: the Mini-Mental State Examination (MMSE), ${ }^{9,10}$ the Brief Cognitive Screening Battery (BCSB), ${ }^{11}$ visual and verbal memory tests (subtest Visual Reproduction of the Wechsler Memory Scale - Revised (WMS-R), ${ }^{12}$ Rey Complex Figure - delayed recall, ${ }^{13}$ subtest Logical Memory (WMS-R), ${ }^{12}$ Rey Auditory Verbal Learning Test (RAVLT),${ }^{14}$ constructive abilities (subtest Block Design -Wechsler Adult Intelligence Scale (WAIS), ${ }^{15}$ Rey Complex Figure copy, ${ }^{13}$ visual perception (Hooper Visual Organization Test ${ }^{16}$ and Raven's Progressive Matrices, ${ }^{17}$ language (Boston Naming Test), ${ }^{18}$ and executive functions (Trail Making Test versions A and B, ${ }^{19}$ Stroop Test ${ }^{19}$ Wisconsin Card Sorting Test (WCST) ${ }^{19}$ and phonemic verbal fluency (F.A.S.). ${ }^{19}$ Information on performance in daily life activities was obtained through the Pfeffer Functional Activities Questionnaire, ${ }^{20}$ which was applied to an informant.

The clinical diagnosis of mild dementia was based on the criteria of the Diagnostic and Statistical Manual of Mental Disorders, Third Edition, revised (DSM-III-R) ${ }^{21}$ and was made by two neurologists (PC and RN), who were blind to DRS and BCSB results, and based on the patients' history, laboratory and neuroimaging results, MMSE scores and on results of the following neuropsychological tasks: constructive abilities (Block Design (WAIS), memory (Rey Auditory Verbal Learning Test (RAVLT) - sum of scores from trials 1 to 5 and the number of words recalled after 30 minutes), language (Boston Naming Test), executive functions (phonemic verbal fluency and Trail Making Test (versions A and B)).
The AD group was composed of 56 individuals, aged 54 to 84 years ( $m e a n=72.98 \pm 7.43$ ), with schooling ranging from 3 to 17 years (mean $=9.62 \pm 4.68$ ), comprising 35 women and 21 men. The diagnosis of probable AD was based on the criteria of the National Institute of Neurological Disorders and Communicative Disorders and StrokeAlzheimer Disease and Related Disorders Association (NINCDS-ADRDA). ${ }^{22}$

Twelve patients were included in the $\mathrm{VaD}$ group, aged 54 to 80 years ( $m e a n=69.41 \pm 8.99)$, with schooling ranging from 4 to 16 years (mean $=8.33 \pm 5.30$ ), comprising 4 women and 8 men (nine cases of subcortical VaD and three cases of multiple infarct dementia). Eleven patients were submitted to MRI of the skull and one to CT. The diagnosis of probable $\mathrm{VaD}$ was based on the criteria of the National Institute of Neurological Disorders and Stroke - Association Internationale pour la Recherche et l'Enseignement en Neurosciences (NINDS- AIREN). ${ }^{23}$

The control group ( 60 subjects; mean age $=68.90 \pm 7.48$; mean schooling $=10.72 \pm 4.74 ; 42$ women and 18 men) was composed of spouses or consorts of the patients, or volunteers from the community, with no memory disorders and who were self-sufficient in terms of daily life activities. Subjects with neurological disease, history of alcoholism, depression, or any other psychiatric disorder, non-corrected visual or auditory disorders, motor disorders, or users of psychotropic drugs that could affect cognitive functions were excluded. Chronic diseases such as arterial hypertension, diabetes mellitus and cardiac disorders, if adequately controlled, were not criteria for exclusion. All controls were submitted to the MMSE, the BCSB and to the Memory Complaint Questionnaire (MAC-Q) (24) or to the Informant Questionnaire on Cognitive Decline in the Elderly (IQCODE), ${ }^{25,26}$ administered to an informant.

The Portuguese version of the DRS ${ }^{17}$ was administered to all patients and controls. The tasks are presented in a fixed order, as recommended by the author, and only the Attention tests are not grouped in a sequence, as they also serve as distractors for the Memory subscale. Within each subscale, the most difficult tests were presented in first and second, and if performed well, subsequent items of the subscale were automatically scored as having been performed correctly. The advantage of this procedure is that it shortens total testing time for individuals who are relatively intact.

The number of points scored for the correct response varies in accordance with the tasks, while the total number of points in each subscale provides a partial score for that subscale. The partial scores are: Attention, 37 points; Initiation/Perseveration, 37 points; Construction, 6 points; Conceptualization, 39 points; and Memory, 25 points. The maximum possible score on the DRS is 144 points. 
In the two groups studied, the scale was applied individually in a single session. The time of application for the group of patients was, on average, 40 minutes, and for the control group, from 20 to 30 minutes.

The study was approved by the Research end Ethics Committee of Hospital das Clínicas of the University of São Paulo School of Medicine. All subjects who agreed to participate signed a written informed consent.

\section{Statistical analysis}

In order to evaluate associations between the categorical variables and the results, the Pearson Chi-Squared test was performed. When the variables were continuous, the comparisons were made for two samples by the Mann-Whitney test, and for more than two, by the Kruskall-Wallis test.

Sensitivity and specificity calculations were performed for each subscale and for the total scale. The cutoff score, calculated through ROC (receiver operator characteristics) curves, was defined as the value presenting the best relationship between sensitivity and specificity.

Alpha risk was considered to be less than or equal to $5 \%$ for type 1 error and beta risk greater than or equal to $20 \%$ for type II error.

All statistical analysis was carried out using the program Statistical Package for the Social Sciences (SPSS), version 10.0.

\section{Results}

There were no statistically significant differences between controls and both patient groups in relation to schooling $(\mathrm{p}=0.213)$ and gender $(\mathrm{p}=0.055)$, but there was a significant difference in relation to age $(\mathrm{p}=0.011)$. A statis- tically significant difference was found between mean total DRS scores of controls and both patients' groups (Table 1).

\section{VaD patients and controls}

In the analysis of the mean total scores on the total scale and each subscale, the I/P subscale $(\mathrm{p}<0.001)$ as well as Memory ( $\mathrm{p}<0.001)$, Conceptualization $(\mathrm{p}<0.001)$ and Attention ( $\mathrm{p}=0.021$ ) subscales differentiated $\mathrm{VaD}$ from controls. The scores in the Construction subscale $(\mathrm{p}=0.150)$ were not significantly different between the two groups. The same phenomenon occurred in the analysis of the areas under curves obtained through the ROC curves (Figure 1) (Table 2).

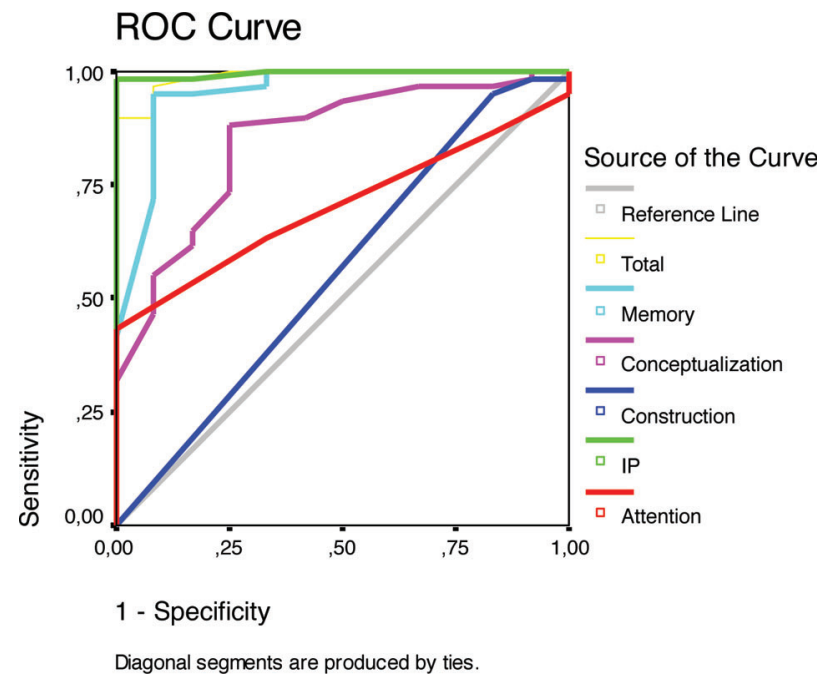

Figure 1. ROC curves of the DRS total score and overall subscales between VaD patients and controls.

Table 1. Performance of patients with VaD and controls, and VaD and AD, DRS total and subscales.

\begin{tabular}{lccccc}
\hline & VaD & controls & $\mathbf{p}$ & AD & p \\
\hline $\mathrm{N}$ & 12 & 60 & & 56 & \\
Total & & & & & \\
Mean (SD) & $110.1(11.0)$ & $136.2(6.3)$ & $<0.0001$ & $113.8(12.4)$ & 0.314 \\
$\begin{array}{l}\text { Attention } \\
\text { Mean (SD) }\end{array}$ & $35.2(0.6)$ & $35.7(1.3)$ & 0.021 & $34.9(1.6)$ & 0.818 \\
$\begin{array}{l}\text { I/P } \\
\text { Mean (SD) }\end{array}$ & $24.6(4.2)$ & $35.1(1.9)$ & $<0.001$ & $29.1(5.8)$ & 0.010 \\
$\begin{array}{l}\text { Construction } \\
\text { Mean (SD) }\end{array}$ & $5.8(0.5)$ & $5.8(0.3)$ & 0.150 & $5.6(1.0)$ & 0.549 \\
$\begin{array}{l}\text { Conceptualization } \\
\text { Mean (SD) }\end{array}$ & $28.2(4.8)$ & $34.5(4.0)$ & $<0.001$ & $29.4(6.0)$ & 0.600 \\
$\begin{array}{l}\text { Memory } \\
\text { Mean (SD) }\end{array}$ & $16.3(4.0)$ & $24.0(1.5)$ & $<0.001$ & $14.7(3.9)$ & 0.325 \\
\hline
\end{tabular}

$\mathrm{N}$, subjects; $\mathrm{I} / \mathrm{P}$, initiation/perseveration; SD, standard deviation; $\mathrm{p}<0.05$. 
Table 2. Areas under the curves, cutoff, sensitivity and specificity for the DRS between VaD patients and controls.

\begin{tabular}{lccccc}
\hline DRS & AUC $(\mathrm{SE})$ & Maximum points & cutoff ${ }^{\star}$ & Sensitivity & Specificity \\
\hline Total & $0.989 \pm 0.010$ & 144 & $<124$ & 93.3 & 91.7 \\
Attention & $0.704 \pm 0.063$ & 37 & $<34$ & 63.3 & 66.7 \\
I/P & $0.996 \pm 0.005$ & 37 & $<29$ & 98.3 & 83.3 \\
Construction & $0.558 \pm 0.097$ & 6 & $<6$ & 95.0 & 16.7 \\
Conceptualization & $0.848 \pm 0.059$ & 39 & $<31$ & 81.7 & 75.0 \\
Memory & $0.953 \pm 0.036$ & 25 & $<21$ & 95.0 & 91.7 \\
\hline
\end{tabular}

DRS, Dementia Rating Scale; AUC, area under curve; SE, standard error; I/P, initiation/perseveration; ${ }^{*}$ individuals with score below the cutoff score are impaired.

\section{VaD and $A D$ patients}

The performance of the AD group on the DRS was compared to the VaD patients' scores (Table 1).

In the comparison between $\mathrm{VaD}$ and $\mathrm{AD}$ patients, only the $\mathrm{I} / \mathrm{P}$ subscale was able to significantly differentiate between the two groups $(\mathrm{p}=0.010)(\mathrm{AUC}=0.739 \pm 0.064 ; \mathrm{p}=0.010)$.

\section{Discussion}

In the present study, the DRS was able to accurately discriminate $\mathrm{VaD}$ patients from controls, while only the I/P subscale differentiated $\mathrm{VaD}$ from $\mathrm{AD}$ patients.

In the discrimination between $\mathrm{VaD}$ patients and control individuals, the cutoff score $<124$ in the DRS showed good sensitivity (93.3\%) and specificity (91.7\%) values.

Both in the analysis of the areas under the curves (AUC) and comparison between the means scores of the two groups, I/P, Memory, Conceptualization and Attention subscales also allowed good discrimination between $\mathrm{VaD}$ patients and controls.

The Memory subscale differentiated VaD patients from normal elderly. Lukatela et al. ${ }^{8}$ verified, in their study comparing DRS scores in $\mathrm{VaD}, \mathrm{AD}$ and controls, that the group with $\mathrm{AD}$ and the group with $\mathrm{VaD}$ presented significant impairment in comparison to the control group. Price et al. ${ }^{29}$ concluded that tests of executive control and memory, along with neuroimaging evidence of involvement of around one-fourth of the cerebral white matter as measured by the Leukoaraiosis Scale, may be sufficient for the diagnosis of subcortical VaD.

The results of the Inasaridze et al..$^{34}$ study demonstrated that attentional deficits are characteristic of $\mathrm{VaD}$. Impaired attention was also observed in other studies, ${ }^{35,36}$ a feature in agreement with our results on the Attention subscale of the DRS.

The Construction subscale was not able to discriminate $\mathrm{VaD}$ patients from controls. This finding seems to be in contrast with the work of Lukatela et al. ${ }^{8}$ in which VaD patients showed greater impairment on this subscale compared to $\mathrm{AD}$ individuals. According to these authors, the results dem- onstrated that problems in simple graphomotor construction and coordination are more pronounced in $\mathrm{VaD}$ than in AD. Perhaps due to the small number of patients in our series, our results differ from those published in the literature.

Patients with $\mathrm{VaD}$ and controls also showed different performances on the Conceptualization subscale in the present study. Giovannetti et al..$^{33}$ investigated different mechanisms that may underlie deficits in verbal concept formation among patients with $\mathrm{AD}$ and ischemic $\mathrm{VaD}$. The test utilized by the authors was the Wechsler Adult Intelligence Scale - Revised (WAIS-R). The Similarities subtest, which contains similar tasks as the Conceptualization subscale, did not differentiate between the two groups. Nonetheless, $\mathrm{AD}$ patients produced a greater proportion of very vague superordinate concepts for the word pairs (for example: $\mathrm{dog} / \mathrm{lion}$ : "they're alive") while the errors produced by $\mathrm{VaD}$ patients demonstrated an inability to provide a superordinate concept for the same word pairs (for example: dog/lion: "the lion roars and the dog barks"). The errors produced by $\mathrm{VaD}$ patients showed impairment in concept formation associated with deficits in executive systems necessary to monitor responses and to sustain mental set. The $\mathrm{AD}$ patients' errors were associated with measures of delayed recognition memory and semantic intrusion errors, indicating that the deficit of concept formation appears to be secondary to impaired verbal response selection.

The comparison between the performances of $\mathrm{VaD}$ and $\mathrm{AD}$ patients on the DRS showed that only the I/P subscale was able to differentiate between the two groups.

Similar results were reported by two independent in-

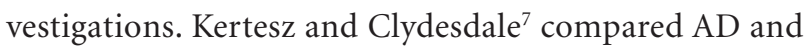
$\mathrm{VaD}$ patients performances on the DRS. VaD patients were significantly worse on motor performance subtests of the $\mathrm{I} / \mathrm{P}$ subscale than $\mathrm{AD}$ patients. The authors concluded that these subtests might be useful in discriminating between $\mathrm{VaD}$ and $\mathrm{AD}$. In the above-mentioned Lukatela et al. study, ${ }^{8}$ $\mathrm{VaD}$ patients with multiple infarcts demonstrated significantly lower scores on the I/P subscale than $\mathrm{AD}$ patients. 
The I/P subscale of DRS is composed by verbal fluency for semantic categories (supermarket items), double simultaneous hand movements and design copy tasks. These two latter tasks evaluate bimanual coordination and motor perseveration, which are recognized to be associated to frontal lobes deficits. According to some authors, ${ }^{27-31}$ the executive dysfunction might serve as diagnostic marker for $\mathrm{VaD}$, especially for the subcortical subtype. Villardita ${ }^{32}$ verified that attention processes, planning and fine motor coordination tasks were more severely impaired in $\mathrm{VaD}$ than in $\mathrm{AD}$ patients, concluding that these disturbances resemble some of those occurring in frontal lobe syndromes. $\mathrm{VaD}$ patients were significantly disadvantaged in executive functions which include planning and sequencing, speed of mental processing, performance on unstructured tasks, and also attention.

In conclusion, the DRS in the present study proved a useful instrument to discriminate between $\mathrm{VaD}$ patients and controls. Our results suggest that executive dysfunction, evaluated through the I/P subscale tasks, is helpful in differentiating $\mathrm{VaD}$ from $\mathrm{AD}$ patients. Further studies involving larger samples of patients are necessary in order to confirm these initial findings.

\section{References}

1. Mattis S. Mental Status Examination for Organic Mental Syndrome in the Elderly Patient. In: Bellak L, Karasu TB, editors. Geriatric Psychiatry. A Handbook for Psychiatrists and Primary Care Physicians. New York: Grune \& Stratton; 1976:77-121.

2. Mattis S. Dementia Rating Scale. Professional manual. Florida: Psychological Assessment Resources; 1988.

3. Monsch AU, Bondi MW, Salmon DP, et al. Clinical Validity of the Mattis Dementia Rating Scale in Detecting Dementia of the Alzheimer Type. Arch Neurol 1995;52:899-904.

4. Porto CS, Charchat-Fichman H, Caramelli P, Bahia VS, Nitrini R. Brazilian version of the Mattis Dementia Rating Scale. Diagnosis of mild dementia in Alzheimer's disease. Arq Neuropsiquiatr 2003;61:339-345.

5. Paolo AM, Trostr AI, Glatt SL, Hubble JP, Koller WCJ. Differentiation of the dementias of Alzheimer's and Parkinson's disease with the dementia rating scale. Geriatr Psychiatry Neurol 1995;8:184-188.

6. Paulsen JS, Butters N, Sadek JR, et al. Distinct cognitive profiles of cortical and subcortical dementia in advanced illness. Neurology 1995;45:951-956.

7. Kertesz A, Clydesdale S. Neuropsychological deficits in Vascular Dementia vs Alzheimer's Disease. Arch Neurol 1994;51:1226-1231.

8. Lukatela K, Cohen R, Kessler H, et al. Dementia Rating Scale Performance: A Comparison of Vascular and Alzheimer's Dementia. J Clin Exper Neuropsych 2000; 22:445-454.

9. Folstein MF, Folstein SE, McHugh PR. "Mini-mental state”. A practical method for grading the cognitive state of patients for the clinician. J Psychiatr Research. 1975;12:189-198.

10. Brucki SMD, Nitrini R, Bertolucci PHP, Caramelli P, Okamoto IH. Normas sugeridas para o uso do Mini-Exame do Estado Mental (MEEM) em nosso meio. Arq Neuropsiquiatr 2003;60:46-47.

11. Nitrini R, Caramelli P, Porto CS, et al. Avaliação cognitiva breve no diagnóstico de doença de Alzheimer leve. Arq Neuropsiquiatr 2005;63:27.

12. Wechsler D. Wechsler Memory Scale. Manual The Psychological Corporation Harcourt Brace Jovanovich; 1987.

13. Rey A. Figuras Complexas de Rey. São Paulo: Casa do Psicólogo; 1998.

14. Diniz LFM, Cruz MF, Torres VM, Consenza RM. O teste de aprendizagem auditivo-verbal de Rey: normas para uma população brasileira. Rev Bras Neurol 2000;36:79-83.

15. Wechsler, D. Test de Inteligencia para adultos (WAIS). Manual. $2^{\text {nd }}$ ed. Buenos Aires: Editorial Paidos; 1993.

16. Hooper Visual Organization Test (VOT) Manual. Los Angeles, CA: Western Psychological Services; 1983.

17. Raven JC, Raven J, Court JH. Manual Matrizes Progressivas Coloridas. São Paulo: Casa do Psicólogo;1988.

18. Radanovic M, Mansur LL, Scaff M. Normative data for the Brazilian population in the Boston Diagnostic Aphasia Examination: influence of schooling. Braz J Med Biol Res 2004;37:1731-1738.

19. Spreen O, Strauss E. A Compendium of Neuropsychological Tests. Administration, Norms, and Commentary. $2^{\text {nd }}$ ed. New York: Oxford University Press; 1998.

20. Pfeffer RI, Kusosaki TT, Harrah Jr CH, Chance JM, Filos S. Measurement of Functional Activities in Older Adults in the Community. J Gerontol 1982;37:323- 329.

21. American Psychiatric Association. Diagnostic and Statistical Manual of Mental Disorders. $3^{\text {rd }}$ ed. Washington, DC: American Psychiatric Association; 1987.

22. McKhann G, Drachman D, Folstein M, Katzman R, Price D, Stadlan EM. Clinical diagnosis of Alzheimer's disease: report of the NINCDS-ADRDA work group under the auspices of department of health and human services task force on Alzheimer's disease. Neurology 1984;34:939-944.

23. Román GC, Tatemichi TK, Erkinjuntti T, et al. Vascular dementia: diagnostic criteria for research studies. Report of the NINDS-AIREN International Work Group. Neurology 1993;43:250-60.

24. Mattos P, Lino V, Rizo L, Alfano A, et al. Memory complaints and test performance in health elderly persons. Arq Neuropsiquiatr 2003;61:920-924.

25. Jorm AF. A short-form of the Informant Questionnaire on Cognitive Decline in the Elderly (IQCODE): development and cross-validation. Psychol Med 1994;24:145-153.

26. Bustamante SEZ, Bottino CMC, Lopes MA, et al. Instrumen- 
tos combinados na avaliação de demência de idosos. Arq Neuropsiquiatr 2003;61:601-606.

27. Mesulam M-M. Principles of Behavioral and Cognitive Neurology. $2^{\text {nd }}$ ed. New York: Oxford University Press; 2000.

28. Lezak MD. Neuropsychological Assessment. $3^{\text {rd }}$ ed. New York: Oxford University Press; 1995.

29. Price CC, Jefferson AL, Merino JG, Heilman KM, Libon DJ. Subcortical vascular dementia: integrating neuropsychological e neuroradiologic data. Neurology. 2005; 65:376-382.

30. Osterman JM, Scherder EJ. Distinguishing between vascular dementia and Alzheimer's disease by means of the WAIS: a meta-analysis. J Clin Exp Neuropsychol 2006;28:1158-1175.

31. O’Brien JT. Vascular cognitive impairment. Am J Geriatr Psychiatry 2006;14:724-733.

32. Villardita C. Alzheimer's disease compared with cerebrovas- cular dementia. Neuropsychological similarities and differences. Acta Neurol Scand 1993;87:299-308.

33. Giovanetti T, Lamar M, Cloud BS, Swenson R, Fein D Kaplan E, Libon DJ. Different underlying mechanisms for deficits in concept formation in dementia. Arch Clin Neuropsychol 2001;16:547-560.

34. Inasaridze K, Sikharulizdze G, Malishava T, Zviadadze M. Attentional disorder in vascular dementia. Georgian Med News. 2006;(135):91-95.

35. Desmond DW. The neuropsychology of vascular cognitive impairment: is there a specific cognitive deficit? J Neurol Sci 2004;226:3-7.

36. Graham NL, Emery T, Hodges JR. Distinctive cognitive profiles in Alzheimer's disease and subcortical vascular dementia. J Neurol Neurosurg Psychiatry 2004;75:61-71. 